\title{
Study of duration and efficacy of chloroprocaine for spinal anesthesia in infraumbilical surgeries
}

\author{
Nazima Memon', R. G. Pathak ${ }^{2}$, Meenakshi S. Pradeep ${ }^{3}$ \\ ${ }^{1}$ Assistant Professor, ${ }^{2}$ Ex-Professor and Head, ${ }^{3}$ Senior Resident, Department of Anaesthesiology, Dr. Shankarrao \\ Chavan Government Medical College, Nanded, Maharashtra, India
}

Background: Spinal anesthesia is a reliable and safe technique for infraumbilical surgeries. Nevertheless, some of its characteristics may limit its use for day care surgery. Use of long-acting anesthetic drugs like bupivacaine in spinal anesthesia may lead to side effects such as delayed ambulation and risk of urinary retention. Chloroprocaine is an amino-ester local anesthetic with a very short half-life now being extensively evaluated in volunteer studies and clinical practice with a favorable safety profile and efficacy, suggesting that it may be a suitable alternative to long-acting local anesthetics like bupivacaine in day care surgeries. Aims and Objectives: This study aims at evaluating the duration and efficacy of chloroprocaine in spinal anesthesia for infraumbilical surgeries. The primary outcome of the study was to evaluate the duration and efficacy of chloroprocaine $1 \%$ in spinal anesthesia for infraumbilical surgeries and the secondary outcome was to find out the incidence of adverse effects if any. Materials and Methods: In this randomized single-blinded clinical evaluation, after institutional ethical committee approval, 30 adult patients (18-70 years, ASA physical Status I-III, BMI $<36 \mathrm{~kg} / \mathrm{m}^{2}$ ) scheduled for infraumbilical surgeries received chloroprocaine $40 \mathrm{mg}$ intrathecally. Patients were evaluated for onset and regression of sensory and motor blockade, peak level of sensory blockade, and time of ambulation postoperatively. Results: The average duration of the surgeries was $46.87 \pm 15.24 \mathrm{~min}$. Anesthesia was sufficient for the planned surgery. Only three patients required sedation intraoperatively. The median peak sensory block height was T8. The mean time for peak height sensory block was $6.6 \pm 1.673 \mathrm{~min}$ and complete motor block was $2 \pm 1.05 \mathrm{~min}$. Mean time for complete sensory block regression was $95.37 \pm 20.79 \mathrm{~min}$ and complete motor block regression was $81.43 \pm 20.33 \mathrm{~min}$. Four patients required inj. atropine following bradycardia and three patients required vasopressors following hypotension. Conclusion: Spinal anesthesia with chloroprocaine provides reliable sensory and motor block for short duration infraumbilical surgeries with fewer intraoperative and post-operative complications.

Key words: Chloroprocaine; Infraumbilical surgeries; Spinal anesthesia; Ambulatory; Short acting

\section{INTRODUCTION}

There is an upward trend of performing day care surgeries worldwide. Many surgeons and anesthetists preferred short general anesthesia over spinal anesthesia for ambulatory surgeries. ${ }^{1}$ Although surgeries of lower abdomen (infraumbilical surgeries) and lower limbs can be safely done under spinal anesthesia, some of the problems
Access this article online

Website:

http://nepjol.info/index.php/AJMS DOI: 10.3126/ajms.v12i11.39107 E-ISSN: 2091-0576

P-ISSN: $2467-9100$

Copyright (c) 2021 Asian Journal of Medical Sciences

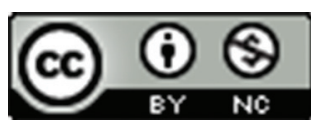

This work is licensed under a Creative Commons Attribution-NonCommercial 4.0 International License. 
ideal technique of anesthesia for day care surgeries. ${ }^{3}$ One of the most important factors which may determine these side effects includes the choice of anesthetic agent used for spinal anesthesia. Until recently, commonly used drugs for spinal anesthesia included bupivacaine and levobupivacaine but they are not of much use in ambulatory surgery because of their long duration of action. ${ }^{4}$ Early ambulation and consequently early discharge mandates that the anesthetic agent should have a rapid onset and early recovery time and should have minimal side effects. As an alternative to long-acting drugs such as bupivacaine and levobupivacaine, lidocaine was used for ambulatory surgical procedures but the search for alternative anesthetic agent was going on in view of increased incidence of transient neurological symptoms associated with the use of lidocaine. ${ }^{5}$

Chloroprocaine is an amino-ester local anesthetic with a very short half-life. It was introduced into clinical practice in 1952, chloroprocaine quickly gained widespread popularity as an epidural drug, particularly in obstetrics, where its rapid hydrolysis by pseudocholinesterase virtually eliminated concern for systemic toxicity and fatal exposure. ${ }^{6}$ Sodium bisulfide was then added as a preservative after $1956 .^{7}$ The drug was then abandoned in the 1980s for several reports of neurological deficits in patients receiving accidentally high doses of intrathecal chloroprocaine during epidural labor analgesia. ${ }^{8}$

However, all these were found to be controversial and $1 \%$ chloroprocaine was reintroduced in 1996 without preservative for clinical use. ${ }^{9}$ It is currently approved in the United States and in Europe. It is FDA approved in India also. ${ }^{10}$

Long-acting local anesthetics such as bupivacaine are routinely used for infraumbilical surgeries. The use of shortacting local anesthetic such as chloroprocaine is expected to have early recovery from spinal anesthesia making it suitable drug for day care surgeries. ${ }^{11}$ Our study aims to highlight this aspect which is not studied much in various studies. Therefore, we undertook this prospective study to evaluate the duration and efficacy of chloroprocaine in spinal anesthesia for infraumbilical surgeries.

\section{MATERIALS AND METHODS}

This was an interventional, single-arm prospective study conducted in the Department of Anesthesiology, Dr. Shankarrao Chavan Government Medical College, Nanded, Maharashtra, over a period of 6 months from June 2020 to December 2020. The institutional ethical committee approved the study. Thirty patients undergoing infraumbilical surgeries such as inguinal hernioplasty and
Jaboulay's hydrocele repair under spinal anesthesia were included in this study on the basis of a predefined inclusion and exclusion criteria. The primary outcome of the study was to evaluate the duration and efficacy of chloroprocaine $1 \%$ in spinal anesthesia for infraumbilical surgeries and the secondary outcome was to find out the incidence of adverse effects if any.

Pre-operative evaluation was done in all the cases. Routine investigations such as complete blood count, bleeding time, clotting time, renal function test, hepatic function test, $\mathrm{HBsAg}$, and HIV were done preoperatively in all the cases. Written informed consent was obtained from all the patients after explaining to them in detail about the procedure they will be undergoing. All patients received preservative-free inj. chloroprocaine $40 \mathrm{mg}$ intrathecally $(5 \mathrm{ml}-50 \mathrm{mg}$ ) for the purpose of spinal anesthesia.

Perioperative vital parameters such as non-invasive blood pressure, pulse rate, oxygen saturation, and intraoperative analgesic requirement was noted. In all the patients, the parameters such as time of spinal anesthesia $\left(\mathrm{T}_{0}\right)$, time of onset of sensory blockade (up to 11 dermatome), peak level of sensory blockade, and time of onset of motor blockade (modified Bromage 3) were determined and noted. The other parameters which were assessed were duration of surgery, time of total regression of sensory blockade, time of total regression of motor blockade (modified Bromage 0 ), time of post-operative ambulation, and any complaints of transient neurologic symptoms (TNS) at $24 \mathrm{~h}$ and 10-day follow-up.

Sample size was calculated according to previous reference studies, when chloroprocaine was used for spinal anesthesia in day care surgeries, as the main result in the event of at least 30 patients was calculated by Open Epi-Version 3 online software, a $10 \%$ difference could be determined between the group at $80 \%$ power and 5\% significance $(\alpha=0.05, \beta=0.80)$.

For statistical purposes, SSPS 21.0 software was used. Microsoft Excel was used for preparation of charts and graphs.

\section{Inclusion criteria}

- Male patients

- Patients posted for infraumbilical surgeries such as inguinal hernioplasty and Jaboulay's hydrocele repair under spinal anesthesia

- Age of the patients should be between 18 and 70 years

- ASA physical Status I-III

- $B M I<36 \mathrm{~kg} / \mathrm{m}^{2}$

- Normal routine blood investigations. 


\section{Exclusion criteria}

The following criteria were excluded from the study:

- Patient refusal

- Bleeding disorders

- Mental disorders

- Allergy to local anesthetics

- Morbid obesity

- Abnormal routine blood investigations such as thrombocytopenia or deranged coagulation profile

- Infection/anatomical deformity

- Hemodynamic instability.

\section{RESULTS}

The analysis of the age group of the studied cases showed that the most common affected age group was between 61 and 70 years $(33.33 \%)$ followed by $31-40$ years $(23.33 \%)$ and $41-50$ years $(16.67 \%)$. The overall mean age of the studied cases was found to be $48.2 \pm 15.3$ years (Figure 1 ).

The analysis of the patients on the basis of surgeries performed showed that the most common surgery performed in the studied cases was unilateral inguinal hernia surgery which was done in $16(53.33 \%)$ patients followed by surgery for hydrocele which was done in $9(30 \%)$ patients. Bilateral hernia as well as hernia and hydrocele surgeries were performed in $2(6.67 \%)$ patients each. Remaining $1(3.33 \%)$ patient underwent surgery (Figure 2).

The duration of surgery depended on type of surgery. In patients in whom hernia as well as hydrocele were operated, the time for surgery was relatively more as compared to isolated hernia or hydrocele repair. The longest duration of surgery was $90 \mathrm{~min}$ and shortest surgery duration was 25 min. The overall mean time for surgery was found to be $46.87 \pm 15.24 \mathrm{~min}$ (Figure 3).

In all patients, average duration for onset of sensory block (up to L1), average duration for onset of motor blockade (Bromage 3), and average duration for peak sensory blockade were noted (Figure 4).

Average duration of onset of sensory block was found to be $1.6 \pm 0.9 \mathrm{~min}$, whereas average duration of onset of motor blockade was found to be $2 \pm 1.05 \mathrm{~min}$. Average duration for onset of peak sensory blockade was found to be $6.6 \pm 1.67 \mathrm{~min}$. Mean peak sensory block height was found to be at the level of T8 (Table 1).

The intraoperative monitoring of vitals such as systolic blood pressure, diastolic blood pressure, and pulse rate was done. Mean systolic blood pressure at 0,5,10, 15, 30, 45, and $60 \mathrm{~min}$ was found to be 128.12, 125.24, 120.68, 123.6, $114,117.5$, and $118.7 \mathrm{~mm}$ of $\mathrm{Hg}$, whereas mean diastolic

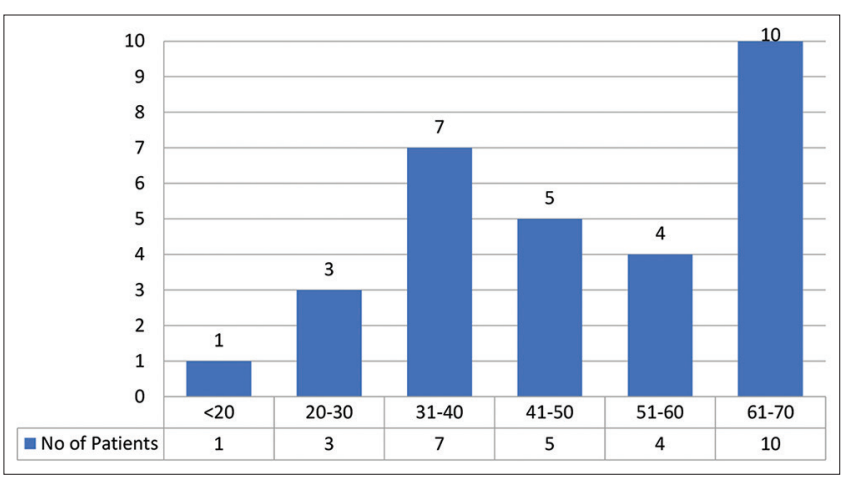

Figure 1: Age distribution of the studied cases

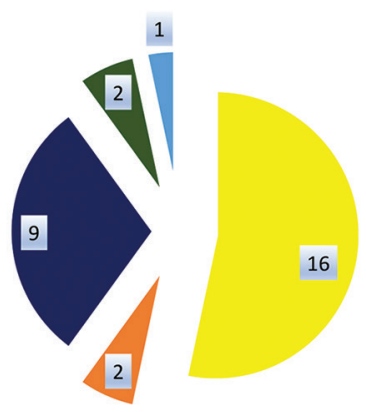

U/L Inguinal Hernia = B/L Hernia "Hydrocele "Both Hernia \& Hydrocele = Others

Figure 2: Surgeries done in studied cases

\begin{tabular}{lc}
$\begin{array}{l}\text { Table 1: Average duration of sensory and motor } \\
\text { blockade as well as duration of onset of peak } \\
\text { sensory block }\end{array}$ & Observation (min) \\
\hline Parameter & $1.6 \pm 0.9$ \\
\hline $\begin{array}{l}\text { Average duration for onset of sensory } \\
\text { block (up to L1) }\end{array}$ & $2 \pm 1.05$ \\
$\begin{array}{l}\text { Average duration for onset of motor } \\
\text { blockade (Bromage } 3 \text { ) } \\
\begin{array}{l}\text { Average duration for onset of peak } \\
\text { sensory block }\end{array}\end{array}$ \\
\hline
\end{tabular}

blood pressure was found to be $78.24,76.36,74.22,72.5$, 70.46, 72.3, and $74.9 \mathrm{~mm}$ of $\mathrm{Hg}$, respectively. The mean pulse rate at $0,5,10,15,30,45$, and $60 \mathrm{~min}$ was found to be $82.4,80.2,78.6,79.5,76.8,78.8$, and 79.3 beats per minute, respectively (Table 2 ).

In $27(90 \%)$ patients, there was no need for analgesia during surgery, whereas $3(10 \%)$ patients required some or the other form of analgesia. Four (13.33\%) patients required atropine for incidence of bradycardia, whereas $3(10 \%)$ patients needed vasopressor for hypotension (Figure 5).

In all patients, average time for complete sensory regression, average time for complete motor regression, and average time duration for post-operative ambulation were determined (Figure 6). 


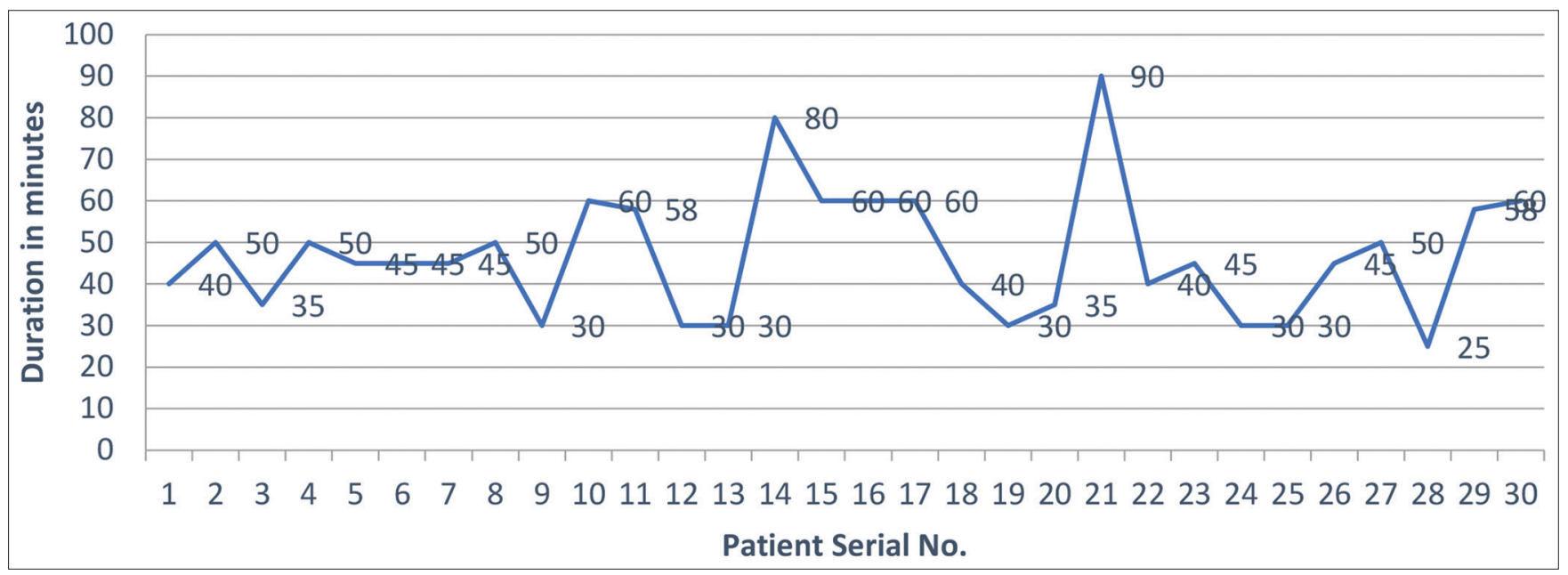

Figure 3: Duration of surgery in studied cases

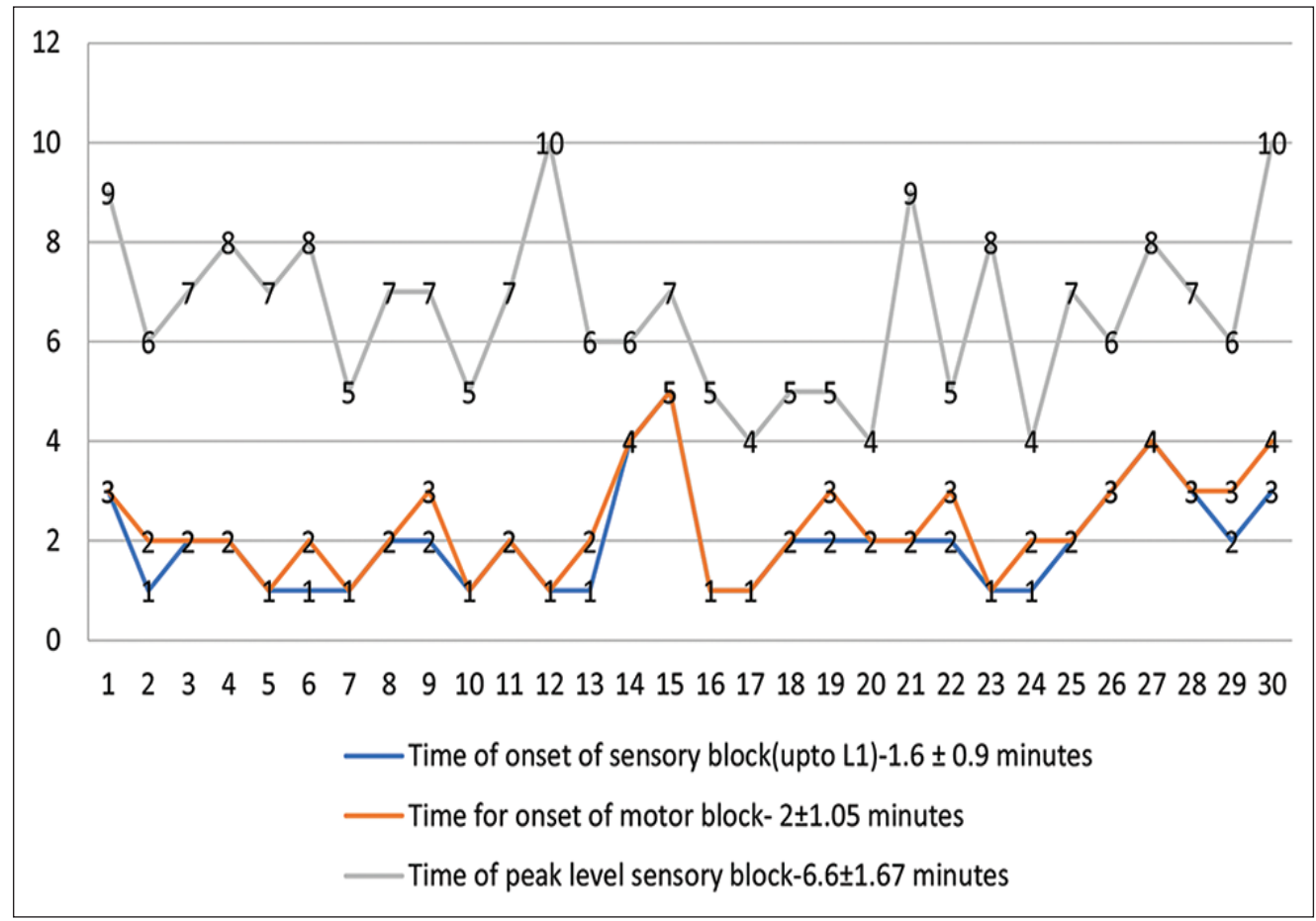

Figure 4: Time of onset of mean sensory and motor block and peak sensory levels

\begin{tabular}{lccc}
$\begin{array}{l}\text { Table 2: Hemodynamic parameters during } \\
\text { surgery }\end{array}$ & \multicolumn{3}{l}{} \\
\hline Time (min) & $\begin{array}{c}\text { Systolic } \\
\text { blood } \\
\text { pressure } \\
\text { (mm of } \mathbf{H g})\end{array}$ & $\begin{array}{c}\text { Diastolic } \\
\text { blood } \\
\text { pressure } \\
\text { (mm of Hg) }\end{array}$ & $\begin{array}{c}\text { Pulse } \\
\text { rate (bpm) }\end{array}$ \\
\hline 0 & 128.12 & 78.24 & 82.4 \\
5 & 125.24 & 76.36 & 80.2 \\
10 & 120.68 & 74.22 & 78.6 \\
15 & 123.6 & 72.5 & 79.5 \\
30 & 114 & 70.46 & 76.8 \\
45 & 117.5 & 72.3 & 78.8 \\
60 & 118.7 & 74.9 & 79.3 \\
\hline
\end{tabular}

In the studied cases, average time for complete sensory regression was found to be $95.37 \pm 20.79 \mathrm{~min}$, whereas average time for complete motor regression was found to be $81.43 \pm 20.33 \mathrm{~min}$. The average time duration for post-operative ambulation was found to be $222 \pm 64.29 \mathrm{~min}$ (Table 3).

Patients were followed up at $24 \mathrm{~h}$ and 10 days postoperatively to look for incidence of transient neurological symptoms (pain and/or dysesthesia in the buttocks and lower extremities). No patient was found to have bradycardia, hypotension, 
or transient neurological symptoms at $24 \mathrm{~h}$. Hypotension was seen in $3(10 \%)$ patients, whereas bradycardia was seen in $4(13.33 \%)$ patients. However, these patients could be managed successfully by atropine and vasopressors.

Table 3: Time for complete sensory and motor
regression and post-operative ambulation

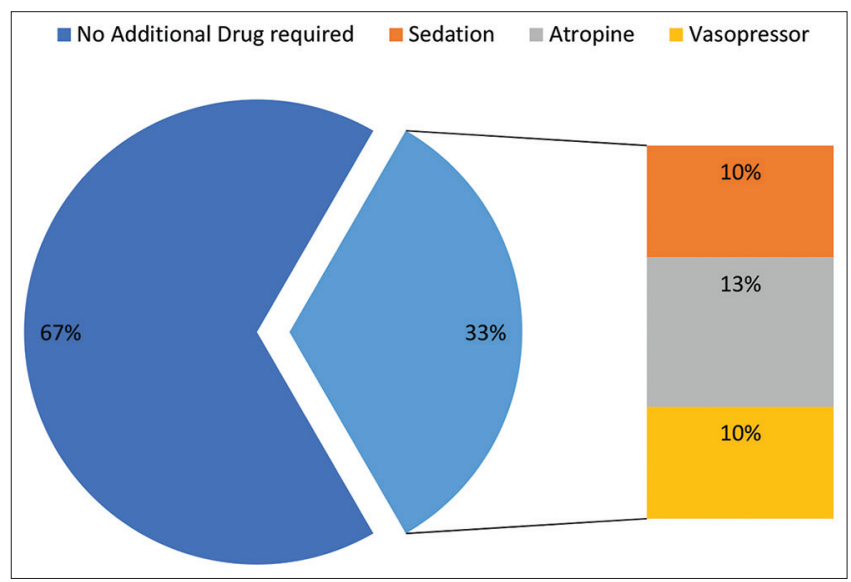

Figure 5: Use of additional drugs in studied cases

\section{DISCUSSION}

This was a prospective study of chloroprocaine as spinal anesthetic in patients undergoing spinal anesthesia. The overall mean age of the studied cases in our study was found to be $48.2 \pm 15.3$ years. Unilateral inguinal hernia Bassini's repair and Jaboulay's repair for hydrocele were found to be the most commonly performed surgery and the mean duration of surgical procedure was found to be $46.87 \pm 15.24 \mathrm{~min}$. In our study, average duration of sensory block was found to be $1.6 \pm 0.9 \mathrm{~min}$, whereas average duration of onset of motor blockade was found to be $2 \pm 1.05 \mathrm{~min}$. Average duration for peak sensory blockade was found to be $6.6 \pm 1.67 \mathrm{~min}$. In the studied cases, average time for complete sensory regression was found to be $95.37 \pm 20.79 \mathrm{~min}$, whereas average time for complete motor regression was found to be $81.43 \pm 20.33 \mathrm{~min}$. The average time duration for post-operative ambulation was found to be $222 \pm 64.29 \mathrm{~min}$. The patient in day care surgeries receiving $1 \%$ chloroprocaine recover faster from effect of spinal anesthesia and can be discharged on the same day.

Sell et al., conducted a prospective study to find out the effective dose of plain 2-chlorprocaine (2-CP) for lower limb surgeries. In this study, 64 ASA physical Status I-III patients undergoing elective lower limb surgery were randomly allocated to one of the four local anesthetic groups for spinal anesthesia in a double-blind manner. The patients ( $\mathrm{n}=16$ patients in each group) received 35 ,

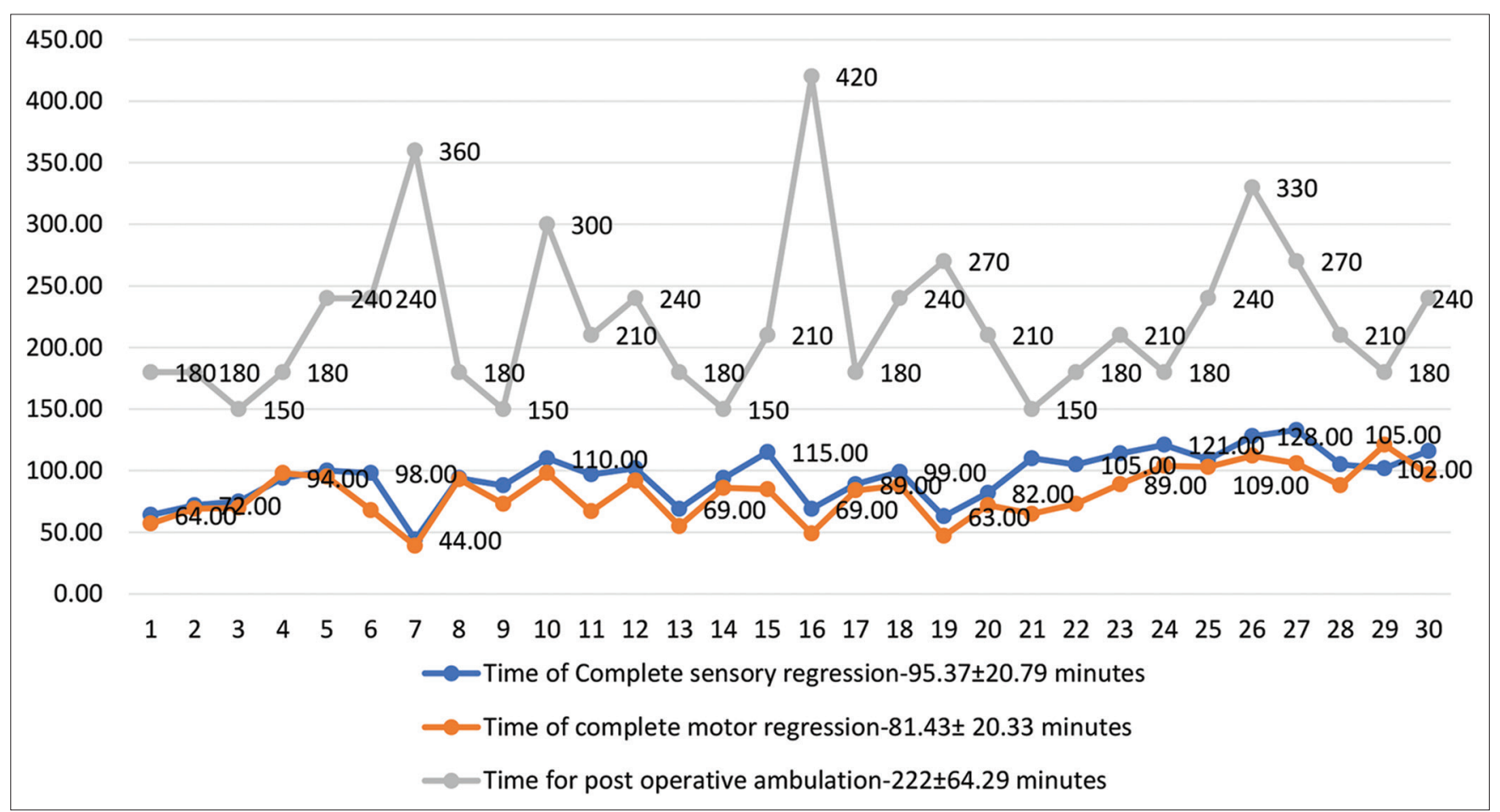

Figure 6: Time for complete sensory and motor regression and post-operative ambulation 
40,45 , or $50 \mathrm{mg}$ of $10 \mathrm{mg} / \mathrm{ml}$ isobaric 2 -CP. The study found that in all patients, anesthesia was sufficient for the planned surgery. The median peak block height (T9) was similar in all four groups $(\mathrm{P}=0.66)$. Time to complete sensory block regression was faster in the $35 \mathrm{mg}$ group (111 min, mean) and in the $40 \mathrm{mg}$ group (108 min) than in the $50 \mathrm{mg}$ group (134 min, $\mathrm{P}=0.005)$. No differences in time to complete motor block regression were observed $(\mathrm{P}=0.3)$. No complications related to spinal anesthesia were observed and no TNSs were reported at the 3-day followup. ${ }^{12}$ The findings of this study were similar to our study particularly there was no case of transient neurological symptoms. Similar findings were also reported by Warren and Kopacz. ${ }^{13}$

In another study, Casati et al., found that the median (range) times for recovery of sensory and motor function, and unassisted ambulation with 2-chlorprocaine were 95 (68-170) min; 60 (45-120) min; and 103 (70-191) min. Similar to our study, Casati et al., also did not find any incidence of transient neurological symptoms. ${ }^{14}$

Kouri et al., conducted a study to compare spinal chloroprocaine and lidocaine in eight volunteers, each receiving two spinal anesthetics. The study found that chloroprocaine produced anesthetic efficacy similar to lidocaine, including peak block height (T8 [T5-11] vs. T8 [T6-12], $\mathrm{P}=0.8183$ ) and tourniquet tolerance (46 $\pm 6 \mathrm{~min}$ vs. $38 \pm 24 \mathrm{~min}, \mathrm{P}=0.4897)$. The authors also reported that chloroprocaine anesthesia resulted in faster resolution of sensory (103 $\pm 13 \mathrm{~min}$ vs. $126 \pm 16 \mathrm{~min}, \mathrm{P}=0.0045)$ and more rapid attainment of simulated discharge criteria (104 \pm 12 min vs. $134 \pm 14 \mathrm{~min}, \mathrm{P}=0.0007)$. On the basis of these findings, the authors concluded that the anesthetic profile of chloroprocaine compares favorably with lidocaine and hence reliable sensory and motor blockade with predictable duration and minimal side effects make chloroprocaine an attractive choice for outpatient spinal anaesthesia. ${ }^{15}$

\section{Limitations of the study}

The limitation of this study was a relatively small number of cases. A study consisting of larger cohort of cases would further substantiate the results of this study.

\section{CONCLUSION}

Chloroprocaine has been found to be an effective shortacting anesthetic agent which can be used intrathecally for short duration infraumbilical and lower extremity surgeries. It has a good safety profile with minimal complications. Moreover, use of $1 \%$ chloroprocaine can be safely implemented for spinal anesthesia in day care surgeries as the patients can be mobilized early and discharged on the same day reducing hospital stay and cost.

\section{ACKNOWLEDGMENT}

The authors would like to acknowledge department of anesthesiology, Dr Shankarrao Chavan Government Medical College Nanded for extending their valuable support in undertaking this study.

\section{REFERENCES}

1. Lee JH. Anaesthesia for ambulatory surgery. Korean J Anesthesiol. 2017;70(4):398-406.

2. de Cassai A, Geraldini F, Boscolo A, Pasin L, Pettenuzzo T, Persona $P$, et al. General anaesthesia compared to spinal anaesthesia for patients undergoing lumbar vertebral surgery: A meta-analysis of randomized controlled trials. J Clin Med. 2020;10(1):102.

https://doi.org/10.3390/jcm10010102

3. Stewart J, Gasanova I, Joshi GP. Spinal anaesthesia for ambulatory surgery: Current controversies and concerns. Curr Opin Anaesthesiol. 2020;33(6):746-752.

https://doi.org/10.1097/aco.0000000000000924

4. Nayagam HA, Singh NR, Singh HS. A prospective randomised double blind study of intrathecal fentanyl and dexmedetomidine added to low dose bupivacaine for spinal anaesthesia for lower abdominal surgeries. Indian J Anaesth. 2014;58(4):430-435. https://doi.org/10.4103/0019-5049.138979

5. Cramer BG, Stienstra R, Dahan A, Arbous MS, Veering BT, van Kleef JW. Transient neurological symptoms with subarachnoid lidocaine: Effect of early mobilization. Eur $\mathrm{J}$ Anaesthesiol. 2005;22(1):35-39.

https://doi.org/10.1017/s0265021505000086

6. Foldes FF, McNall PG. 2-Chloroprocaine: A new local anesthetic agent. Anaesthesiology. 1952;13(3):287-296.

https://doi.org/10.1097/00000542-195205000-00009

7. Takenami T, Hiruma H, Kaneko H, Okamoto H, Kawakami T. Effects of sodium bisulfite with or without procaine derivatives on axons of cultured mouse dorsal root ganglion neurons. Reg Anesth Pain Med. 2015;40(1):62-67. https://doi.org/10.1097/aap.0000000000000195

8. Bauer M, George JE $3^{\text {rd }}$, Seif J, Farag E. Recent advances in epidural analgesia. Anesthesiol Res Pract. 2012;2012:309219.

9. Herndon CL, Martinez R, Sarpong NO, Geller JA, Shah RP, Cooper HJ. Spinal anaesthesia using chlorprocaine is safe, effective, and facilitates earlier discharge in selected fast-track total hip arthroplasty. Arthroplast Today. 2020;6(3):305-308. https://doi.org/10.1016/j.artd.2020.04.007

10. Camponovo C, Wulf H, Ghisi D, Fanelli A, Riva T, Cristina D, et al. Intrathecal $1 \% 2$-chlorprocaine vs. $0.5 \%$ bupivacaine in ambulatory surgery: A prospective, observer-blinded, randomised, controlled trial. Acta Anaesthesiol Scand. 2014;58(5):560-566. https://doi.org/10.1111/aas.12291

11. Bhaskara B, Shruthi S, Ramachandraiah R. A study to evaluate intrathecal $1 \%$ chlorprocaine and $0.5 \%$ levobupivacaine in perianal surgeries: A prospective randomized study. Anesth Essays Res. 2020;14(3):406-411.

https://doi.org/10.4103/aer.aer_2_21 
12. Sell A, Tein T, Pitkanen M. Spinal 2-chloroprocaine: Effective dose for ambulatory surgery. Acta Anaesthesiol Scand. 2008;52(5):695-699.

https://doi.org/10.1111/j.1399-6576.2008.01639.x

13. Warren DT, Kopacz DJ. Spinal 2-chlorprocaine: The effect of added dextrose. Anesth Analg. 2004;98(1):95-101.

14. Casati A, Fanelli G, Danelli G, Berti M, Ghisi D, Brivio M, et al. Spinal anaesthesia with lidocaine or preservative-free 2-chlorprocaine for outpatient knee arthroscopy: A prospective, randomized, double-blind comparison. Anesth Analg. 2007;104(4):959-964.

https://doi.org/10.1213/01.ane.0000258766.73612.d8

15. Kouri ME, Kopacz DJ. Spinal 2-chlorprocaine: A comparison with lidocaine in volunteers. Anesth Analg. 2004;98(1): 75-80.

\footnotetext{
Authors Contribution:

NM - Concept and design of the study, prepared first draft of manuscript; RP - Interpreted the results, reviewed the literature, and manuscript preparation

MP - Concept, coordination, statistical analysis and interpretation, preparation of manuscript, and revision of the manuscript.

Work attributed to:

Department of Anaesthesiology, Dr. Shankarrao Chavan Government Medical College, Nanded.

Orcid ID:

Dr. Nazima Memon - (1) https://orcid.org/0000-0002-5584-6746

R. G. Pathak - (1) https://orcid org/0000-0002-7580-3479

Dr. Meenakshi S. Pradeep - (i) https://orcid.org/0000-0002-9040-6412

Source of Support: Nil, Conflicts of Interest: None.
} 